\title{
Knowledge, attitude and practices of South African healthcare professionals towards complementary and alternative medicine use for atopic eczema - a descriptive survey
}

\author{
Yasmeen Thandara* (D), Julia Botha $^{b}$ (D), Benn Sartorius ${ }^{c}$ iD and Anisa Mosam ${ }^{d}$ \\ ${ }^{a}$ Department of Basic Medical Sciences, Faculty of Heath Sciences, Durban University of Technology, Durban, South Africa \\ ${ }^{b}$ Discipline of Pharmaceutical Sciences, Division of Pharmacology, University of KwaZulu-Natal, Durban, South Africa \\ 'Department of Public Health, School of Nursing and Public Health, University of KwaZulu-Natal, Durban, South Africa \\ ${ }^{d}$ Department of Dermatology, Nelson Mandela School of Medicine, University of KwaZulu-Natal, Durban, South Africa \\ *Corresponding author, email:yasmeent@dut.ac.za
}

\begin{abstract}
Background: Complementary and alternative medicines (CAM) are used widely for treating atopic eczema (AE), commonly in conjunction with conventional medicines prescribed by mainstream healthcare professionals (HCPs). This cross-sectional survey evaluated the knowledge, general attitudes and practices regarding CAM among dermatologists, paediatricians, general practitioners (GPs) and pharmacists treating patients with AE in Durban, KwaZulu-Natal.

Methods: Questionnaires were sent via email or hand-delivered to HCPs nearby.

Results: Of the 330 respondents, 220 (67\%) were males and 110 (33\%) females. Most (40\%) were > 50 years. GPs and pharmacists were significantly more embracing of CAM compared with dermatologists and paediatricians. The majority were not familiar with most CAMs for AE. More GPs (29\%) and pharmacists (43\%) recommend CAM compared with dermatologists (8\%) and paediatricians (5\%). GPs and pharmacists were also amenable to referring patients to CAM practitioners. The majority do not initiate discussions with their patients regarding CAM use nor enquire when taking a history. Many dermatologists (65\%) and pharmacists (51\%) reported that their patients ask about CAM. All dermatologists, $95 \%$ of paediatricians, $87 \%$ of GPs and $55 \%$ of pharmacists reported having no training in CAM but believed it should be included in their curriculum. Most are interested in learning about CAM and agreed that it would better prepare them in managing patients.

Conclusion: This study demonstrated poor CAM knowledge and communication between HCPs and patients but a strong interest amongst HCPs to learn more. There is an urgent need for continuing education programmes and inclusion in undergraduate curriculums, which will assist HCPs in influencing better patient outcomes.
\end{abstract}

Keywords: atopic dermatitis, atopic eczema, attitudes, complementary and alternative medicine, complementary medicine, healthcare professionals, knowledge, practices, views

\section{Background}

Atopic eczema (AE) is one of the most common skin diseases affecting patients who present to dermatological practices in South Africa (SA). ${ }^{1}$ Over the last decade, the lifetime prevalence of physician-diagnosed AE has almost doubled in SA. ${ }^{2}$ This rise continues despite accessible effective treatments. ${ }^{3}$ Due to $A E^{\prime} s$ chronic, relapsing nature and the unattainability of complete clinical cure, patients are continually exploring complementary and alternative medicines (CAM) in search of a cure. ${ }^{3}$ CAM's popularity in the management of $\mathrm{AE}$ is well established. ${ }^{4}$

Non-compliance with therapy is a major contributor to AE's persistence. Reported non-compliance rates are 30-60\% with most regimes. ${ }^{5}$ Common reasons cited for non-compliance were apprehension of the danger of steroids, concern about side effects of other prescribed medication and a preference for 'natural' therapy. ${ }^{5}$ This presents a dilemma for practitioners for many reasons: unproven effectiveness of many CAM, less funding for medication with proven reliability, difficulty in evaluating treatment and perpetuation of 'natural' therapists' perspectives that steroids are dangerous, resulting in long-term suffering. ${ }^{5}$

Although evident from the literature that patients have embraced $\mathrm{CAM}^{3}{ }^{3}$ healthcare professionals (HCP) may not be as embracing. Their attitude and knowledge of CAMs will influence their proactiveness in enquiring about CAM and confidently discussing proven/unproven remedies with their patients, thereby influencing an overall positive clinical experience and disease course.

Several international studies have explored the knowledge, attitudes and practices amongst general practitioners (GPs), physicians, pharmacists, paediatricians, academic doctors and other healthcare workers towards CAM..$^{6-11}$ These studies focused on general CAM use and none within the context of a specific disease. We found no published studies conducted in SA or elsewhere investigating $\mathrm{HCPs}^{\prime}$ knowledge, attitudes and norms of practice with regard to CAMs for AE. Given the extensive use among South African patients with $A E,^{12}$ the views and rationales among South African HCPs treating patients with $\mathrm{AE}$ requires investigation.

\section{Objectives}

We conducted a cross-sectional survey among mainstream HCPs treating patients with AE in Durban, KwaZulu-Natal, with the aim of exploring their knowledge, awareness of use, recommendations, practices and attitudes to CAM use amongst their AE patients. 


\section{Methods}

The Ethics Committee of University of KwaZulu-Natal provided approval (BE219/14).

\section{Study population}

Practising dermatologists, paediatricians, GPs and pharmacists in Durban were selected randomly using professional societies' databases and the telephone directory. HCPs had to be practising in a private practice where they treat AE patients; however, dermatologists and paediatricians were also considered if they consult in the public sector. Sample sizes were calculated based on population estimates of each group of HCPs represented in this study in Durban and surrounding areas (within $20 \mathrm{~km}$ ).

Participants were recruited between October 2014 and February 2015. A total of $330 \mathrm{HCPs}$ responded to the survey: $25 / 34$ dermatologists ( $74 \%$ response rate); $41 / 61$ paediatricians $(67 \%$ response rate); $182 / 570$ general practitioners (33\% response rate); $82 / 158$ retail pharmacists (52\% response rate).

\section{Data collection}

Participants were sent an email with a link to the questionnaire. Questionnaires were also hand-delivered to HCPs practising nearby. Three reminders were sent electronically and via telephone calls.

The questionnaire covered the following sections:

- practitioner and practice particulars;

- general and demographic particulars of the HCP.

- views on/attitudes to CAM for eczema;

- knowledge of CAM for eczema;

- professional practices with regard to CAM;

- education regarding CAM for eczema.

\section{Statistical analyses}

Data was analysed using Stata $13.0^{\circledR}$ (StataCorp LP, College Station, TX, USA). Categorical data were summarised using frequencies and percentages. Association between type of HCP and attitudes, familiarity and practice using CAM variables were assessed using the Pearson chi-square test and Fisher's exact test if any cell count contained fewer than five expected observations. We considered a $p$-value $<0.05$ as being statistically significant.

\section{Results}

\section{Demographics}

The $330 \mathrm{HCPs}$ respondents comprised 26 dermatologists, 40 paediatricians, $182 \mathrm{GPs}$ and 82 pharmacists. There were 220 (67\%) males and 110 (33\%) females; 113 (34\%) were Muslim practitioners, 104 (32\%) Hindu, 99 (30\%) Christian and 1 (0.3\%) Buddhist. Two were atheist (0.6\%), 1 agnostic $(0.3 \%)$ and 10 did not respond (3\%). The majority (132) were $>50$ years (40\%), 105 (32\%) were $31-40$ years, $76(23 \%)$ were $41-50$ years and $17(5 \%)$ were $<30$ years. The majority were Indian practitioners (71\%), 48 (15\%) White, 42 (13\%) Black and 7 (2\%) Coloured.

Our study demonstrated that there was no statistically significant demographic factor, e.g. age, gender, religion or ethnicity, that was a predictor of HCPs' knowledge, attitudes and practices towards CAM.
Table 1: South African healthcare professionals' views/attitudes towards CAM

\begin{tabular}{|c|c|c|c|}
\hline Statement & Agree & Disagree & Neutral \\
\hline \multicolumn{4}{|c|}{$\begin{array}{l}\text { 1. CAM provides a more holistic approach to health than conventional } \\
\text { medicines }(p=0.002)\end{array}$} \\
\hline Dermatologists $(n=26)$ & $8 \%$ & $46 \%$ & $42 \%$ \\
\hline Paediatricians $(n=40)$ & $13 \%$ & $45 \%$ & $43 \%$ \\
\hline General practitioners $(n=182)$ & $32 \%$ & $24 \%$ & $45 \%$ \\
\hline Pharmacists $(n=82)$ & $29 \%$ & $22 \%$ & $49 \%$ \\
\hline \multicolumn{4}{|c|}{ 2. Most CAM are safe and have very few side effects $(p=0.013)$} \\
\hline Dermatologists $(n=26)$ & $15 \%$ & $42 \%$ & $38 \%$ \\
\hline Paediatricians $(n=40)$ & $23 \%$ & $45 \%$ & $33 \%$ \\
\hline General practitioners $(n=182)$ & $29 \%$ & $34 \%$ & $37 \%$ \\
\hline Pharmacists $(n=82)$ & $37 \%$ & $23 \%$ & $40 \%$ \\
\hline \multicolumn{4}{|c|}{$\begin{array}{l}\text { 3. CAM can offer patients benefits that conventional medicines cannot } \\
(p=0.001)\end{array}$} \\
\hline Dermatologists $(n=26)$ & $8 \%$ & $46 \%$ & $42 \%$ \\
\hline Paediatricians $(n=40)$ & $18 \%$ & $48 \%$ & $35 \%$ \\
\hline General practitioners ( $n=182$ ) & $36 \%$ & $24 \%$ & $41 \%$ \\
\hline Pharmacists $(n=82)$ & $35 \%$ & $23 \%$ & $41 \%$ \\
\hline
\end{tabular}

4. The results of complementary therapies are due to the placebo effect $(p<0.001)$

$\begin{array}{lccc}\text { Dermatologists }(n=26) & 27 \% & 12 \% & 58 \% \\ \text { Paediatricians }(n=40) & 45 \% & 8 \% & 48 \% \\ \text { General practitioners }(n=182) & 16 \% & 40 \% & 43 \% \\ \text { Pharmacists }(n=82) & 11 \% & 46 \% & 43 \%\end{array}$

5. Patients whose physicians are knowledgeable about CAM practices, in addition to conventional medicine, have better clinical outcomes $(p<0.001)$

$\begin{array}{llll}\text { Dermatologists }(n=26) & 23 \% & 12 \% & 62 \% \\ \text { Paediatricians }(n=40) & 20 \% & 25 \% & 55 \% \\ \text { General practitioners }(n=182) & 52 \% & 12 \% & 37 \% \\ \text { Pharmacists }(n=82) & 59 \% & 7 \% & 34 \%\end{array}$

6. Physicians should have knowledge about the most prominent CAM treatments $(p=0.013)$

$\begin{array}{llll}\text { Dermatologists }(n=26) & 69 \% & 8 \% & 19 \% \\ \text { Paediatricians }(n=40) & 73 \% & 10 \% & 18 \% \\ \text { General practitioners }(n=182) & 81 \% & 2 \% & 17 \% \\ \text { Pharmacists }(n=82) & 83 \% & 5 \% & 12 \%\end{array}$

7. While we need to be cautions in our claims, a number of CAM therapies hold promise for the treatment of symptoms, conditions and/or diseases $(p<0.001)$

$\begin{array}{lccc}\text { Dermatologists }(n=26) & 31 \% & 19 \% & 46 \% \\ \text { Paediatricians }(n=40) & 25 \% & 10 \% & 65 \% \\ \text { General practitioners }(n=182) & 55 \% & 4 \% & 41 \% \\ \text { Pharmacist }(n=82) & 0 \% & 0 \% & 0 \%\end{array}$

8. CAM therapies should be subjected to more scientific testing before being accepted by conventional doctors $(p=0.886)$

\begin{tabular}{llll} 
Dermatologists $(n=26)$ & $96 \%$ & $0 \%$ & $4 \%$ \\
Paediatricians $(n=40)$ & $88 \%$ & $3 \%$ & $10 \%$ \\
General practitioners $(n=182)$ & $87 \%$ & $2 \%$ & $11 \%$ \\
Pharmacists $(n=82)$ & $87 \%$ & $1 \%$ & $12 \%$ \\
\hline
\end{tabular}

(Continued) 
Table 1: (Continued)

\begin{tabular}{lccc}
\hline Statement & Agree & Disagree & Neutral \\
\hline $\begin{array}{l}\text { 9. CAM can produce longer lasting and } \\
\text { conventional medicines }(p=0.003)\end{array}$ & $0 \%$ & $58 \%$ & $42 \%$ \\
\hline $\begin{array}{l}\text { Dermatologists }(n=26) \\
\text { Paediatricians }(n=40)\end{array}$ & $3 \%$ & $53 \%$ & $45 \%$ \\
\hline General practitioners $(n=182)$ & $17 \%$ & $29 \%$ & $54 \%$ \\
\hline Pharmacists $(n=82)$ & $11 \%$ & $34 \%$ & $55 \%$ \\
\hline 10. I am annoyed when I find out my patients are using CAM without telling \\
me ( $p=0.034)$ \\
\hline Dermatologists $(n=26)$
\end{tabular}

\section{HCPs' views/attitude towards CAM}

Views/attitudes were assessed by the degree of agreement with general statements regarding CAM. Fewer specialists (8\% dermatologists and $13 \%$ paediatricians) felt that CAM provides a more holistic healthcare approach compared with GPs (32\%) and pharmacists $(29 \%)(p=0.002)$. Again, fewer specialists $(8 \%$ dermatologists and $18 \%$ paediatricians) felt that CAM can offer benefits over conventional medicines compared with GPs (36\%) and pharmacists (35\%) $(p=0.001)$. Regarding the perception that the results from CAM are due to a placebo effect, more specialists ( $45 \%$ paediatricians and $27 \%$ dermatologists) than GPs $(16 \%)$ and pharmacists $(11 \%)$ were of this opinion $(p<0.001)$. More GPs $(52 \%)$ and pharmacists (59\%) felt that if physicians were more knowledgeable about CAM practices, their patients would have better clinical outcomes $(p<0.001)$. None of the dermatologists and only $3 \%$ of paediatricians felt that CAM produced a more complete clinical cure than conventional medicines. This was significantly less than the views of GPs (14\%) and pharmacists $(16 \%)(p=0.037)$. More dermatologists (35\%) and paediatricians (30\%) felt that CAM interferes with standard medical care compared with GPs and pharmacists (both 15\%) $(p<0.001)$.

These results are represented in Table 1.

\section{HCPs' familiarity regarding CAM}

The percentage of HCPs that reported being very familiar with any of the CAMs frequently used for AE were low. Most were slightly familiar with probiotics and dietary supplements. However, it was evident that all HCPs were unfamiliar with the majority of the CAMs listed in Table 2, with higher levels of unfamiliarity regarding Chinese herbal medicines (CHM) and homeopathy. GPs and pharmacists were more familiar with oral and topical herbal products than dermatologists and paediatricians.

HCPs' familiarity is shown in Table 2.

\section{$H C P s^{\prime}$ professional practices regarding CAM}

The majority of HCPs never/rarely initiate discussions regarding CAM for $\operatorname{AE}(p=0.006)$ and only sometimes have discussions with patients when a patient requests a CAM (no difference across HCP groups was noted) ( $p=0.698)$. Although most reported not being confident in discussing CAM therapies with their patients, the majority reported that they always believe that HCPs treating patients for AE should regularly ask about CAM use. In general, most HCPs were unhappy to refer patients to CAM practitioners. More specialists (54\% of dermatologists

Table 2: South African healthcare professionals' familiarity regarding CAM

\begin{tabular}{|c|c|c|c|}
\hline CAM therapy & Unfamiliar & $\begin{array}{l}\text { Slightly } \\
\text { Familiar }\end{array}$ & $\begin{array}{c}\text { Very } \\
\text { Familiar }\end{array}$ \\
\hline \multicolumn{4}{|l|}{ 1. Homeopathy $(p<0.001)$} \\
\hline Dermatologists $(n=26)$ & $69 \%$ & $15 \%$ & $12 \%$ \\
\hline Paediatricians $(n=40)$ & $83 \%$ & $15 \%$ & $3 \%$ \\
\hline $\begin{array}{l}\text { General practitioners } \\
(n=182)\end{array}$ & $60 \%$ & $34 \%$ & $7 \%$ \\
\hline Pharmacists $(n=82)$ & $41 \%$ & $48 \%$ & $11 \%$ \\
\hline \multicolumn{4}{|c|}{ 2. Chinese herbal medicines $(p<0.001)$} \\
\hline Dermatologists $(n=26)$ & $54 \%$ & $35 \%$ & $8 \%$ \\
\hline Paediatricians $(n=40)$ & $93 \%$ & $8 \%$ & $0 \%$ \\
\hline $\begin{array}{l}\text { General practitioners } \\
(n=182)\end{array}$ & $87 \%$ & $9 \%$ & $4 \%$ \\
\hline Pharmacists $(n=82)$ & $84 \%$ & $12 \%$ & $4 \%$ \\
\hline \multicolumn{4}{|l|}{ 3. Probiotics $(p<0.001)$} \\
\hline Dermatologists $(n=26)$ & $27 \%$ & $58 \%$ & $12 \%$ \\
\hline Paediatricians $(n=40)$ & $40 \%$ & $45 \%$ & $15 \%$ \\
\hline $\begin{array}{l}\text { General practitioners } \\
(n=182)\end{array}$ & $35 \%$ & $45 \%$ & $21 \%$ \\
\hline Pharmacists $(n=82)$ & $22 \%$ & $33 \%$ & $45 \%$ \\
\hline \multicolumn{4}{|c|}{ 4. Dietary supplements ( $p=0.002)$} \\
\hline Dermatologists $(n=26)$ & $35 \%$ & $50 \%$ & $12 \%$ \\
\hline Paediatricians $(n=40)$ & $28 \%$ & $63 \%$ & $10 \%$ \\
\hline $\begin{array}{l}\text { General practitioners } \\
(n=182)\end{array}$ & $23 \%$ & $51 \%$ & $26 \%$ \\
\hline Pharmacists $(n=82)$ & $13 \%$ & $54 \%$ & $33 \%$ \\
\hline \multicolumn{4}{|c|}{ 5. Oral herbal products, e.g. evening primrose oil, borage oil $(p<0.001)$} \\
\hline Dermatologists $(n=26)$ & $50 \%$ & $23 \%$ & $23 \%$ \\
\hline Paediatricians $(n=40)$ & $68 \%$ & $28 \%$ & $5 \%$ \\
\hline $\begin{array}{l}\text { General practitioners } \\
(n=182)\end{array}$ & $38 \%$ & $48 \%$ & $13 \%$ \\
\hline Pharmacists $(n=82)$ & $17 \%$ & $57 \%$ & $26 \%$ \\
\hline \multicolumn{4}{|c|}{ 6. Topical herbal creams, e.g. calendula, chamomile, St John's Wort $(p<0.001)$} \\
\hline Dermatologists $(n=26)$ & $46 \%$ & $42 \%$ & $8 \%$ \\
\hline Paediatricians $(n=40)$ & $58 \%$ & $40 \%$ & $3 \%$ \\
\hline $\begin{array}{l}\text { General practitioners } \\
(n=182)\end{array}$ & $41 \%$ & $46 \%$ & $14 \%$ \\
\hline Pharmacists $(n=82)$ & $17 \%$ & $61 \%$ & $22 \%$ \\
\hline
\end{tabular}


and $45 \%$ of paediatricians) reported never being happy to refer patients to CAM practitioners compared with GPs (25\%) and pharmacists (22\%).

HCPs' professional practice habits are shown in Table 3.

\section{HCPs' recommendation of CAM}

Most South African HCPs do not recommend CAM for AE. However, in comparison, the majority of specialists (92\% dermatologists and $95 \%$ paediatricians) do not recommend CAM compared with GPs $(71 \%)$ and pharmacists $(57 \%)(p<0.001)$. This reflects a substantial number of GPs and pharmacists that do recommend CAM. Figure 1 represents these results.

Table 3: South African healthcare professionals' practices regarding CAM

\begin{tabular}{lccccc}
\hline Statement & Always & Never & Often & Rarely & Sometimes \\
\hline $\begin{array}{l}1 . \text { I initiate a discussion with patients regarding } \\
(p=0.006)\end{array}$ & & & & & \\
Dermatologists $(n=26)$ & $0 \%$ & $65 \%$ & $4 \%$ & $12 \%$ & $19 \%$ \\
$\begin{array}{l}\text { Permeir eczema } \\
\text { Paediatricians }(n=40)\end{array}$ & $0 \%$ & $55 \%$ & $5 \%$ & $28 \%$ & $13 \%$ \\
$\begin{array}{l}\text { General practitioners } \\
(n=182)\end{array}$ & $4 \%$ & $29 \%$ & $12 \%$ & $31 \%$ & $24 \%$ \\
$\quad$ Pharmacists $(n=82)$ & $7 \%$ & $31 \%$ & $9 \%$ & $23 \%$ & $29 \%$ \\
\hline
\end{tabular}

2. I have a discussion when a patient requests CAM for their eczema $(p=0.698)$

\begin{tabular}{|cccccc}
\hline Dermatologists $(n=26)$ & $4 \%$ & $19 \%$ & $23 \%$ & $19 \%$ & $34 \%$ \\
\hline $\begin{array}{c}\text { Paediatricians }(n=40) \\
\text { General practitioners }\end{array}$ & $5 \%$ & $15 \%$ & $15 \%$ & $30 \%$ & $35 \%$ \\
$\begin{array}{c}(n=182) \\
\quad \text { Pharmacists }(n=82)\end{array}$ & $13 \%$ & $12 \%$ & $19 \%$ & $22 \%$ & $36 \%$ \\
\hline
\end{tabular}

3. I ask about CAM use when taking a medication history for a new patient $(p=0.110)$

\begin{tabular}{|c|c|c|c|c|c|}
\hline Dermatologists $(n=26)$ & $0 \%$ & $27 \%$ & $31 \%$ & $23 \%$ & $19 \%$ \\
\hline Paediatricians $(n=40)$ & $18 \%$ & $23 \%$ & $13 \%$ & $18 \%$ & $30 \%$ \\
\hline $\begin{array}{l}\text { General practitioners } \\
(n=182)\end{array}$ & $18 \%$ & $20 \%$ & $26 \%$ & $16 \%$ & $20 \%$ \\
\hline Pharmacists ( $n=82$ ) & $15 \%$ & $10 \%$ & $22 \%$ & $24 \%$ & $29 \%$ \\
\hline \multicolumn{6}{|c|}{ 4. I am confident discussing CAM therapies with patients $(p=0.036)$} \\
\hline Dermatologists $(n=26)$ & $4 \%$ & $42 \%$ & $12 \%$ & $31 \%$ & $12 \%$ \\
\hline Paediatricians $(n=40)$ & $5 \%$ & $35 \%$ & $8 \%$ & $35 \%$ & $18 \%$ \\
\hline $\begin{array}{l}\text { General practitioners } \\
(n=182)\end{array}$ & $6 \%$ & $25 \%$ & $13 \%$ & $33 \%$ & $23 \%$ \\
\hline Pharmacists $(n=82)$ & $10 \%$ & $12 \%$ & $10 \%$ & $30 \%$ & $38 \%$ \\
\hline
\end{tabular}

5 . I believe that health practitioners treating patients for their eczema should regularly ask patients if they are using CAM therapies $(p=0.138)$

\begin{tabular}{cccccc} 
Dermatologists $(n=26)$ & $54 \%$ & $0 \%$ & $23 \%$ & $0 \%$ & $23 \%$ \\
\hline $\begin{array}{c}\text { Paediatricians }(n=40) \\
\text { General practitioners }\end{array}$ & $30 \%$ & $3 \%$ & $35 \%$ & $8 \%$ & $25 \%$ \\
$\begin{array}{c}(n=182) \\
\text { Pharmacists }(n=82)\end{array}$ & $57 \%$ & $1 \%$ & $29 \%$ & $2 \%$ & $10 \%$
\end{tabular}

6. I am happy to refer patients to CAM practitioners e.g. Homeopaths, herbalists etc. for complementary treatment for their eczema $(p=0.002)$

\begin{tabular}{cccccc}
\hline Dermatologists $(n=26)$ & $0 \%$ & $54 \%$ & $0 \%$ & $35 \%$ & $12 \%$ \\
\hline Paediatricians $(n=40)$ & $3 \%$ & $45 \%$ & $5 \%$ & $25 \%$ & $23 \%$ \\
$\begin{array}{c}\text { General practitioners } \\
(n=182)\end{array}$ & $8 \%$ & $25 \%$ & $9 \%$ & $19 \%$ & $38 \%$ \\
$\quad$ Pharmacists $(n=82)$ & $13 \%$ & $22 \%$ & $7 \%$ & $21 \%$ & $37 \%$ \\
\hline
\end{tabular}

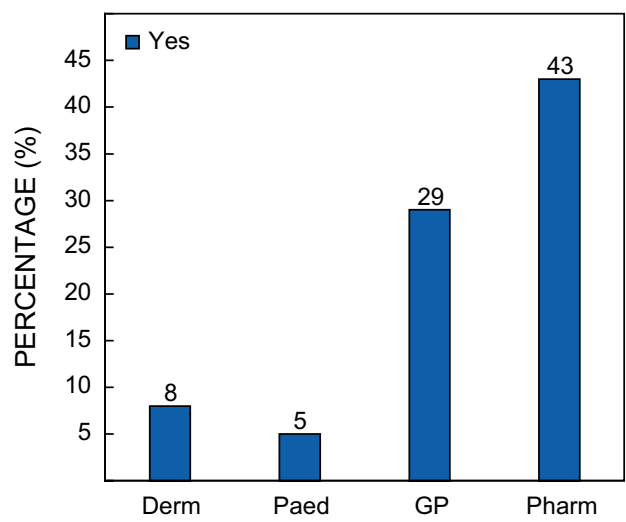

Figure 1: Percentage of healthcare professionals that recommend CAM for eczema $(p<0.001)$.

\section{Patients requesting CAM}

More than half of the dermatologists (65\%) and pharmacists $(51 \%)$ reported that their patients ask questions about or request CAMs for AE. Fewer paediatricians (33\%) and GPs (36\%) reported this $(p=0.005)$.

\section{HCPs' knowledge/education regarding CAM}

All dermatologists and most paediatricians (95\%) and GPs (85\%) had no training in CAM compared with $55 \%$ of pharmacists $(p<0.001)$. A larger number of specialists did not access medical journals $(p<0.001)$, the internet $(p=0.005)$ or have discussions with other colleagues regarding CAM ( $p=$ 0.037) compared with GPs and pharmacists. Comparatively, pharmacists were among the HCPs who sourced CAM information most often. The majority of paediatricians (85\%), GPs (83\%) and pharmacists (82\%) reported that CAM is never discussed at meetings whereas more than half of the dermatologists reported CAM being discussed in congresses ( $p$ $<0.001$ ). Table 4 reflects these results.

\section{HCPs' perspectives on CAM education}

On assessing the HCPs' perspectives on CAM education, the majority responded positively to universities including CAM as part of the curriculum $(p=0.001)$. Most agreed that learning about CAM would better prepare them for treating patients with $\operatorname{AE}(p=0.004)$ and the majority were interested in learning more about CAM for $\mathrm{AE}(p=0.004)$. These results are shown in Figure 2.

\section{Discussion}

\section{Attitudes}

The widespread use of CAM for AE among patients worldwide has been documented..$^{13}$ Data have also revealed extensive use among South African AE patients. ${ }^{12}$ We thus explored the knowledge, attitudes and practices of South African HCPs in respect of CAM for $A E$.

The attitudes among HCPs in our study varied. Those with specialist training (dermatologists and paediatricians) were more sceptical, uncertain about the value and less receptive towards CAM compared with GPs and pharmacists who were significantly more positive and embracing of CAM. 


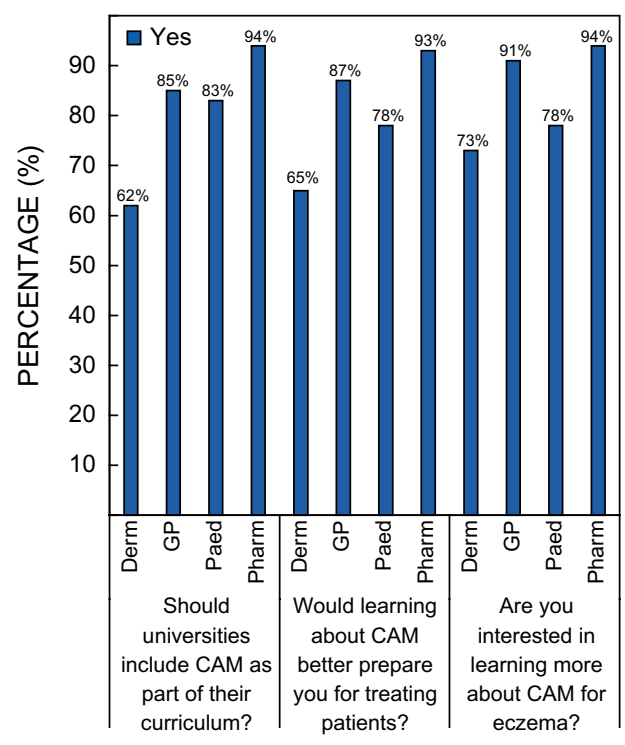

Figure 2: South African healthcare professionals' perspectives on CAM education.

Table 4: South African healthcare professionals' education regarding CAM

\begin{tabular}{|c|c|c|c|}
\hline Statement & No & $\begin{array}{c}\text { Yes, but } \\
\text { minimal/rarely }\end{array}$ & $\begin{array}{c}\text { Yes, substantial/ } \\
\text { frequently }\end{array}$ \\
\hline \multicolumn{4}{|c|}{ 1. Did you have any training on CAM? $(p<0.001)$} \\
\hline Dermatologists $(n=26)$ & $100 \%$ & $0 \%$ & $0 \%$ \\
\hline Paediatricians $(n=40)$ & $95 \%$ & $3 \%$ & $3 \%$ \\
\hline $\begin{array}{l}\text { General practitioners } \\
(n=182)\end{array}$ & $87 \%$ & $8 \%$ & $4 \%$ \\
\hline Pharmacists $(n=82)$ & $55 \%$ & $37 \%$ & $9 \%$ \\
\hline
\end{tabular}

2. Do you access any medical journals to source information on CAMs for eczema? $(p<0.001)$

\begin{tabular}{|cccc|}
\hline Dermatologists $(n=26)$ & $77 \%$ & $15 \%$ & $8 \%$ \\
\hline $\begin{array}{c}\text { Paediatricians }(n=40) \\
\begin{array}{c}\text { General practitioners } \\
(n=182)\end{array}\end{array}$ & $83 \%$ & $10 \%$ & $8 \%$ \\
\hline $\begin{array}{l}\text { Pharmacists }(n=82) \\
\text { Pherm }\end{array}$ & $44 \%$ & $26 \%$ & $6 \%$ \\
\hline
\end{tabular}

3. Do you access any information on the internet with regard to CAMs for eczema? $(p=0.006)$

\begin{tabular}{|cccc|}
\hline Dermatologists $(n=26)$ & $62 \%$ & $27 \%$ & $12 \%$ \\
\hline Paediatricians $(n=40)$ & $68 \%$ & $25 \%$ & $8 \%$ \\
$\begin{array}{c}\text { General practitioners } \\
(n=182)\end{array}$ & $59 \%$ & $31 \%$ & $9 \%$ \\
$\quad$ Pharmacists $(n=82)$ & $35 \%$ & $45 \%$ & $20 \%$
\end{tabular}

4. Do you have discussions with other colleagues about CAM use for eczema? $(p=0.034)$

\begin{tabular}{|cccc|}
\hline $\begin{array}{c}\text { Dermatologists }(n=26) \\
\text { Paediatricians }(n=40)\end{array}$ & $62 \%$ & $38 \%$ & $0 \%$ \\
$\begin{array}{c}\text { General practitioners } \\
(n=182)\end{array}$ & $64 \%$ & $30 \%$ & $0 \%$ \\
\hline $\begin{array}{l}\text { Pharmacists }(n=82) \\
\text { 5. Is CAM for eczema discussed in congresses you have attended? }(p<0.001)\end{array}$ & $5 \%$ \\
\hline $\begin{array}{l}\text { Dermatologists }(n=26) \\
\text { Paediatricians }(n=40)\end{array}$ & $35 \%$ & $58 \%$ & $8 \%$ \\
\hline $\begin{array}{l}\text { General practitioners } \\
(n=182)\end{array}$ & $85 \%$ & $15 \%$ & $0 \%$ \\
\hline \begin{tabular}{l} 
Pharmacists $(n=82)$ \\
\hline
\end{tabular} & $82 \%$ & $15 \%$ & $2 \%$ \\
\hline
\end{tabular}

This positive attitude was seen in several other studies. A Texasbased study reported that a large number of GPs were positive about incorporating CAM into general practice (75\%), referring patients to CAM practitioners (>60\%) and offering proven CAM therapies to patients (70\%). ${ }^{10}$ Saudi Arabian primary healthcare physicians also showed a positive attitude and $76 \%$ believed that CAM would lead to a better patient outcome. ${ }^{14}$ GPs in a Qatar survey reflected support of CAM with $83 \%$ agreeing that it is a useful supplement to conventional medicine and included ideas and methods beneficial to the primary care physician. ${ }^{6}$ The overall attitudes of Australian GPs and pharmacists towards CAM are positive. ${ }^{15}$ In a South African-based study among pharmacists, almost half $(47 \%)$ believed in the benefits of both conventional and herbal medicines and $64 \%$ perceived herbs to be therapeutically effective drugs. ${ }^{16}$ Our survey shows a similar positive attitude among GPs and pharmacists.

Conversely, certain studies have demonstrated scepticism and uncertainty about CAM's value. The majority of academic doctors with dual academic and clinical roles in a Bristol, UK study expressed doubt due to the lack of scientific evidence. ${ }^{9}$ This scepticism is seen amongst South African specialists (dermatologists and paediatricians) in our survey with many also having dual academic and clinical roles. The Texas-based study among GPs reported that in comparison with another study using the same instrument, a more positive attitude was seen among primary care practitioners compared with nonprimary care peers (sub-speciality physicians) at the Mayo Clinic. ${ }^{10} \mathrm{GPs}$ are generally based within the community and are exposed to a variety of diseases for which patients are using CAM. This type of family medical practice seems a more open forum for patients and doctors to discuss CAM choices, thus realising a more open approach from GPs. A study among paediatricians in the Netherlands, however, found a positive attitude towards CAM, mostly towards probiotics and dietary supplements whose action can be rationalised with those of conventional medicines.

\section{Familiarity}

The scepticism among HCPs can be attributed to their lack of knowledge. On assessing knowledge/familiarity, it was evident that the majority were unfamiliar with most CAMs for AE. GPs and pharmacists were more familiar with herbal products (oral and topical) compared with specialists. Higher levels of unfamiliarity were seen with CHM and homeopathy, possibly because the theory behind their action differs vastly from conventional medicine, as well as the limited exposure to $\mathrm{CHM}$ practitioners in Durban. Another Durban-based study amongst healthcare workers in HIV/AIDS clinics reflected poor CAM knowledge including homeopathy and CHM. ${ }^{11}$ Likewise, $81 \%$ of Turkish dermatologists reported very little/no knowledge of CAM and more than half of paediatricians surveyed in the Netherlands also had little knowledge of CAM therapies. ${ }^{17}$ Studies among GPs in Qatar and Saudi Arabia reported similar poor CAM knowledge (39\% and $>63 \%$ respectively). ${ }^{6,14}$ However, several Australian surveys indicate that GPs are familiar with a wide range of CAM therapies. ${ }^{15}$ Australian pharmacists reported that while a lack of knowledge about safety was a definite barrier to their recommendation, they still often recommended CAM alongside conventional medicines as part of the pharmacy protocol. ${ }^{7}$

\section{Recommendations and referrals}

Although most HCPs do not recommend CAM to their patients, more GPs (29\%) and pharmacists (43\%) do so compared with dermatologists (8\%) and paediatricians (5\%). Similarly, more GPs 
and pharmacists were amenable to referring patients compared with the specialists (Table 3). Both practices are reflective of their general attitudes towards CAM. The concern is that those recommending CAM are doing so without adequate knowledge/ training. This lack of knowledge/training was reported among the majority of respondents in our study but did vary depending on CAM type. Recommendations despite knowledge were seen among Turkish dermatologists where $80 \%$ reported little/no knowledge, yet more than half have at some stage recommended topical herbal therapies and a significant proportion other herbal therapies. ${ }^{17}$ With regard to referrals, $50 \%$ of paediatricians in a Michigan, USA study said that they would refer patients to CAM practitioners whereas only $27 \%$ of paediatricians in the Netherlands occasionally refer patients. ${ }^{18}$ In a survey among Durban pharmacists, only $8 \%$ considered themselves sufficiently equipped to advise patients, yet $45 \%$ indicated that they did counsel patients on herbal medicines and these were recommended by $36 \%$ of respondents. In a Texas-based study, almost half (42\%) of the primary HCPs did refer patients to CAM practitioners and $64 \%$ would like to. ${ }^{10}$ Referral rates were low among Qatar GPs where 39\% stated that they had poor CAM knowledge. ${ }^{6}$ A greater number of doctors in Australia (68\%) were in favour of referring patients to complementary therapists and most were familiar with various CAM therapies. ${ }^{15}$

\section{Communication}

Although fewer HCPs in our survey recommend or refer patients to CAM practitioners, a fair number are doing so. Fewer paediatricians (33\%) and GPs (36\%) said that their patients ask about CAM compared with a larger number of dermatologists (65\%) and pharmacists (51\%). It appears that patients frequently ask for CAM for skin diseases. On assessing HCPs' practices when treating patients, our study indicated that the majority of South African HCPs do not initiate discussions with their patients regarding their CAM use. Even when a patient requests/asks about CAM it is not their practice always to discuss this with patients. Most do not even enquire about the patient's CAM use when taking a medical history. The majority reported a lack of confidence in discussing CAM therapies. This is undoubtedly due to their lack of knowledge as confirmed through this study.

Despite these practices, most believed that HCPs treating patients for AE should regularly ask patients if they are using CAM and most agreed that it is necessary for practitioners to have knowledge of the most prominent CAM treatments. As pharmacies are the major stockists of CAM products, patients expect pharmacists to have sufficient knowledge to advise them. This is an important aspect of a pharmacist's service. This reluctance is discussing CAM issues with patients is also seen in other studies. In the Netherlands, the majority of paediatricians seldom discuss CAM use with parents and among paediatricians in Michigan, USA, discussions regarding CAM were found to be mostly initiated by parents $(85 \%) .{ }^{18,19}$ Even primary healthcare physicians in Saudi Arabia who claimed to be comfortable in counselling patients on certain types of CAM commonly used in their region were reluctant to initiate discussions regarding their patients' CAM practices. ${ }^{14}$ Among GPs in Texas, USA, 84\% stated that their patients initiated discussions around $\mathrm{CAM}^{10}$ On the other hand, a national Australian survey indicated that a large number of GPs who practice integrative medicine $(66 \%)$ as well as almost half $(47 \%)$ of those not practising integrative medicine do initiate CAM discussions with patients and a similar number also ask about its use when taking a history. ${ }^{20}$

\section{Education}

Our survey revealed that most South African HCPs acknowledge their lack of knowledge on CAM and want to be better informed. This lack of knowledge is due to lack of training in CAM in both the undergraduate and continuing education programmes. All dermatologists, $95 \%$ of paediatricians and $87 \%$ of GPs reported having no training in CAM. Pharmacists, on the other hand, have had a little more CAM training (45\%). The majority of respondents believed that universities should include CAM as part of their curriculum. A similar number also agreed that learning about CAM would better prepare them for managing patients and are interested in learning more. These views correlate with other studies which have recommended that CAM be included in undergraduate medical and pharmacy curricula. ${ }^{7,16}$ Among Saudi Arabian primary healthcare physicians, $85 \%$ agreed that they should have knowledge of CAM. ${ }^{14}$ In Qatar, almost all GPs (98\%) were interested to learn more about CAM and most dermatologists in a study in Turkey also claimed that they would like to be better informed about CAM. ${ }^{17}$ In a survey amongst paediatricians in Michigan, USA, 54\% were keen on continuing medical education courses for CAM. ${ }^{18}$ Academic doctors in Bristol, UK acknowledged that better doctor-patient communication and patient disclosure is required; however, their views on educating themselves on CAM were varied. ${ }^{9}$ Our survey was comparable to most as the majority of HCPs (> 72\% specialists, $>90 \%$ GPs and pharmacists) said that they wanted to learn more about CAM for AE.

\section{Limitations}

Although this study has been compared with those in other countries, our study was reflective of CAM practices specifically for AE whereas those of other countries were on general use of CAM. It is presumed that the attitudes, knowledge and practices of CAM for AE would be similar to CAM use in other contexts. The responses in the study may not represent the views of all South African HCPs as our study sample were majority Indian HCPs within the Durban metropolitan area.

\section{Conclusion}

It is clear that CAM is an established therapy for a large part of the population and, considering that CAM and conventional medicine are often used together, there is a potential for confusion in attribution of therapeutic benefits, adverse effects and drug interactions. Their concomitant use also creates a potential for non-compliance with prescribed therapy affecting overall clinical outcome. It is imperative that HCPs initiate discussions as well as realise and accept a responsibility in understanding their evidence-based role. HCPs need to become more conversant with common CAM therapies in order to influence better patient management and possibly better outcomes. Our study demonstrated poor CAM knowledge and communication between $\mathrm{HCP}$ and patient but a strong interest amongst HCPs to learn more.

Funding - This work was supported by The National Research Foundaton Thuthuka Funding Instrument [TTK14061769473].

\section{References}

1. Dlova NC, Mankahla A, Madala N, et al. The spectrum of skin diseases in a black population in Durban, KwaZulu-Natal, South Africa. Int J Dermatol. 2015;54(3):279-85. http://dx.doi.org/10.1111/ijd.2015.54. issue-3

2. Deckers IA, McLean S, Linssen S, et al. Investigating international time trends in the incidence and prevalence of atopic eczema 19902010: a systematic review of epidemiological studies. PLoS ONE. 2012;7(7):e39803. http://dx.doi.org/10.1371/journal.pone.0039803 
3. Johnston GA, Bilbao RM, Graham-Brown RAC. The use of complementary medicine in children with atopic dermatitis in secondary care in Leicester. Br J Dermatol. (1951). 2003;149(3):566-71. http://dx.doi.org/10.1046/j.1365-2133.2003.05471.x

4. Ernst E, Ernst E. The usage of complementary therapies by dermatological patients: a systematic review. $\mathrm{Br} J$ Dermatol. (1951). 2000;142(5):857-61. http://dx.doi.org/10.1046/j.13652133.2000.03463.x

5. Fischer G. Compliance problems in paediatric atopic eczema. Australas J Dermatol. 1996;37(s1):S10-3. http://dx.doi.org/10.1111/ ajd.1996.37.issue-s1

6. AIShaar IAMS, Ismail MFS, Yousuf WAAA, et al. Knowledge, attitudes and practice of general practitioners towards complementary and alternative medicine in Doha, Qatar/Connaissances, attitudes et pratique des medecins generalistes en matiere de medecine complementaire et alternative a Doha. East Mediterr Health J. 2010;16(5):522-27.

7. Culverhouse SE, Wohlmuth $H$. Factors affecting pharmacists' recommendation of complementary medicines-a qualitative pilot study of Australian pharmacists. BMC complement Altern Med. 2012;12:183-94.

8. Vlieger AM, van Vliet M, Jong MC. Attitudes toward complementary and alternative medicine: a national survey among paediatricians in the Netherlands. Eur J Pediatr. 2011;170:619-24. http://dx.doi. org/10.1007/s00431-010-1331-3

9. Maha N, Shaw A. Academic doctors' views of complementary and alternative medicine (CAM) and its role within the NHS: an exploratory qualitative study. BMC complement Altern Med. 2007;7(1):17-27. http://dx.doi.org/10.1186/1472-6882-7-17

10. Zhang Y, Peck K, Spalding M, et al. A study to examine the attitudes, knowledge, and utilization of CAM by primary care professional in West Texas. Complement Ther Med. 2010;18(6):227-32. http://dx.doi.org/10.1016/j.ctim.2010.09.009

11. Mbutho NP, Gqaleni N, Korporaal CM. Traditional complementary and alternative medicine: knowledge, attitudes and practices of health care workers in HIV and AIDS clinics in Durban hospitals. Afr J Tradit Complement Altern Med. 2012;9(3 Suppl):64-72.

12. Thandar Y, Botha J, Sartorius B, et al. Complementary and alternative medicine use among patients with atopic eczema-a South African perspective. Cape Town: Unity in Dermatology Congress; 2016.

13. Ernst E. Prevalence of use of complementary/alternative medicine: a systematic review. Bull World Health Organ. 2000;78(2):252-7.

14. Abdullah Al-Rowais N, Al Bedah AM, Khalil MK, El Olemy AT, Khalil AA, Alrasheid $\mathrm{MH}$, et al. Knowledge and attitudes of primary health care physicians towards complementary and alternative medicine in the Riyadhregion,SaudiArabia.ForschKomplementmed.2012;19(1):7-12. http://dx.doi.org/10.1159/000335814

15. Easton K. Complementary medicines: attitudes and information needs of consumers and healthcare professionals - prepared for the National Prescribing Service Limited (NPS). Sydney: NPS. 2007 July;2007:1-72.

16. Brijlal N, Khoza N, Mbonane N, Meyiwa S, Moodley S, Parbhoo T, et al. The attitudes and knowledge of pharmacists towards the use of herbal medicine. S Afr Pharm J. 2011;78(7):35-7.

17. Göker K, Kürşat G, Hamza Y, et al.The knowledge and attitudes towards complementary and alternative medicine among dermatologists in Turkey. Archives of the Turkish Dermatology \& Venerology/Turkderm. 2015;49(1):31-6.

18. Sikand A, Laken M. Pediatricians' experience with and attitudes toward complementary/alternative medicine. Arch Pediatr Adolesc Med. 1998;152(11):1059-64.

19. Vlieger AM, van Vliet M, Jong MC. Attitudes toward complementary and alternative medicine: a national survey among paediatricians in the Netherlands. Eur J Pediatr. 2011;170: 619-24.

20. Pirotta M, Kotsirilos V, Brown J, et al. Complementary medicine in general practice-a national survey of GP attitudes and knowledge. Aust Fam Physician. 2010;39(12):946-50.

Received: 09-07-2016 Accepted: 26-09-2016 